\title{
The stringent response of Bacillus anthracis contributes to sporulation but not to virulence
}

\begin{abstract}
Correspondence
Willem van Schaik

w.vanschaik@umcutrecht.nl
\end{abstract}

Received 5 June 2007

Revised 25 July 2007

Accepted 22 August 2007

\author{
Willem van Schaik, ${ }^{1,2} \dagger$ Julie Prigent ${ }^{1,2}$ and Agnès Fouet ${ }^{1,2}$ \\ ${ }^{1}$ Unité Toxines et Pathogénie Bactérienne, Institut Pasteur, 28 rue du Dr Roux, \\ 75724 Paris Cedex 15, France \\ ${ }^{2}$ CNRS, URA 2172
}

\section{INTRODUCTION}

Bacillus anthracis is a Gram-positive sporulating bacterium, and causes the disease anthrax. The infectious cycle of $B$. anthracis starts when spores are taken up by a mammalian host. Upon germination of the spores inside the host, vegetative cells synthesize different virulence factors, by far the most important of which are two toxins and a capsule (Mock \& Fouet, 2001). Binary combinations of protective antigen (PA) with either lethal factor (LF) or oedema factor (EF) constitute the toxins. PA, LF and EF are encoded by the genes pagA, lef and cya, respectively. These three genes are carried by pXO1, a $181 \mathrm{~kb}$ plasmid, and are organized as independent transcriptional units. The B. anthracis capsule is composed of poly- $\gamma$-D-glutamate. A five-gene operon, capBCADE, encodes the enzymes responsible for capsule synthesis and anchoring (Candela \& Fouet, 2005; Candela et al., 2005), and this operon is harboured by $\mathrm{pXO} 2$, a $96 \mathrm{~kb}$ plasmid. The main function of the capsule is the inhibition of phagocytosis during infection (Mock \&

tPresent address: Department of Medical Microbiology, University Medical Center Utrecht, Heidelberglaan 100, 3584 CX Utrecht, The Netherlands.

Abbreviations: ILV, isoleucine, leucine and valine; PA, protective antigen.
Fouet, 2001). Upon infection, the host dies from a combination of toxaemia and septicaemia. As B. anthracis mainly infects herbivores, vegetative cells generally find themselves in the soil upon the death of the host and the decomposition of its carcass (Dragon et al., 2005). B. anthracis has a limited ability to grow in soil (Van Ness, 1971; Jensen et al., 2003; Saile \& Koehler, 2006) and vegetative cells of $B$. anthracis therefore form endospores, thereby completing the infectious cycle (Mock \& Fouet, 2001).

Two important conditions favouring the expression of $B$. anthracis virulence factors are the presence of a $\mathrm{CO}_{2}-$ bicarbonate equilibrium and a temperature of $37{ }^{\circ} \mathrm{C}$ (Sirard et al., 1994; Fouet \& Mock, 1996). These conditions are specifically encountered in the mammalian host. In vitro studies in liquid media have revealed that the three toxin genes are coordinately regulated under these conditions. Their rate of transcription increases throughout exponential growth, reaching a maximum upon entry into stationary phase. The regulatory mechanisms that control toxin gene expression are not fully understood (Fouet \& Mock, 2006). An important regulator is AtxA, which is encoded by a gene situated on pXO1. It activates toxin gene expression, capsule formation and other chromosomally or 
plasmid-encoded genes (Uchida et al., 1993; Guignot et al., 1997; Mignot et al. 2003; Bourgogne et al. 2003). The alternative sigma factor $\sigma^{\mathrm{H}}$ and the transition-state regulator AbrB have been shown to control at $x A$ transcription and consequently toxin gene expression (Saile \& Koehler, 2002; Strauch et al., 2005; Hadjifrangiskou et al., 2007). The mode of action of AtxA is still unclear, but recently it has been suggested that its activity can be increased or decreased by phosphorylation of two different histidine residues (Tsvetanova et al., 2007).

The maximal expression of toxin genes occurs at the end of exponential phase, upon entry into stationary phase, suggesting a link between nutrient limitation and toxin gene expression in B. anthracis. However, sporulation is also triggered by nutrient limitation, and these two stationary-phase responses appear to be mutually exclusive (White et al., 2006). An important bacterial response to starvation is called the stringent response (for a recent review, see Braeken et al., 2005). It is characterized by a rapid down-regulation of stable RNA synthesis upon amino acid starvation. The accumulation of the effector molecules ppGpp and pppGpp is an important hallmark of the stringent response. These nucleotides are synthesized by enzymic phosphorylation of GDP and GTP to ppGpp and pppGpp, respectively, using ATP as a phosphate donor. In Escherichia coli, in which the stringent response was first studied (Cashel et al., 1996), the proteins SpoT and RelA catalyse this reaction. In Gram-positive bacteria, the protein RelA, which combines the functions of E. coli SpoT and RelA, appears to be the only protein involved in the production of (p)ppGpp (Mittenhuber, 2001). In the non-pathogenic Gram-positive model organism Bacillus subtilis, relA is necessary for efficient sporulation (Eymann et al., 2001). In the non-sporulating Gram-positive pathogens Mycobacterium tuberculosis, Listeria monocytogenes and Streptococcus mutans, the deletion of the relA gene affects virulence properties (Taylor et al., 2002; Dahl et al., 2003; Lemos et al., 2004).

In this study we generated a relA deletion mutant in $B$. anthracis, and using this mutant we were able to show that relA is essential for (p)ppGpp accumulation and downregulation of stable RNA synthesis upon amino acid starvation. We could not detect a role for relA in the expression of pagA or in virulence in a mouse model of infection. However, sporulation in a defined medium was affected in the relA mutant, leading to approximately 10000 -fold lower spore counts for the relA mutant than for the parental strain. Our data indicate that the stringent response of $B$. anthracis may be important for the persistence and spread of $B$. anthracis in the environment by contributing to the process of sporulation.

\section{METHODS}

Strains and culture conditions. The strains used were $B$. anthracis $7702\left(\mathrm{pXO}^{+}, \mathrm{pXO}^{-}\right), \mathrm{RPG}\left(\mathrm{pXO}^{+}, \mathrm{pXO} 2^{+}, \mathrm{Tox}^{-}\right)$and the pagA-lacZ and atxA-lacZ promoter reporter strains RBAF140 and
7702XFI, respectively (Collection de l'Institut Pasteur; Gimenez et al., 2004; Sirard et al., 1994; Guidi-Rontani et al., 1999). For pre-cultures, strains were grown overnight in $20 \mathrm{ml}$ brain heart infusion (BHI) broth with $0.5 \%(\mathrm{v} / \mathrm{v})$ glycerol in $100 \mathrm{ml}$ Erlenmeyer flasks at $37{ }^{\circ} \mathrm{C}$ with rotary shaking at 150 r.p.m. Bacterial growth was determined by measuring $\mathrm{OD}_{600}$ with an Ultrospec 3300pro spectrophotometer (Amersham Pharmacia Biotech) using cuvettes with a $1 \mathrm{~cm}$ path length. When cultures reached $\mathrm{OD}_{600}>0.5$, samples were diluted fourfold with the growth medium as diluent prior to the measurement.

Generation of relA deletion mutants in B. anthracis. The relA mutant was first made in strain 7702 and was constructed by allelic replacement of a $1.6 \mathrm{~kb}$ internal fragment of relA with a non-polar kanamycin-resistance cassette. To obtain this mutant a $2.8 \mathrm{~kb}$ fragment containing the relA gene with $0.5 \mathrm{~kb}$ up- and $0.1 \mathrm{~kb}$ downstream flanking regions was PCR-amplified using the primers Rel5' (5'-CGCATTAGAAGTAGGATTTGCGCCAGTTCG-3') and Rel3' (5'-CCGAACGGAATTTGTCCTACGATCTCACCG-3'). This fragment was cloned into pCR2.1 (Invitrogen), resulting in pRel10. This vector was then digested with SpeI, followed by blunting of the overhang with Vent DNA polymerase, and PstI digestion. The resulting product was cloned into pUC18, which was digested by SmaI and PstI, resulting in pRel15. Subsequently, a $1.5 \mathrm{~kb}$ kanamycinresistance cassette, which was obtained by ClaI digestion from pAT21 (Trieu-Cuot \& Courvalin, 1983) and subsequent blunting of overhangs, was inserted in pRel15, which was digested by BamHI and EcoRV and blunted. This replaces a $1.6 \mathrm{~kb}$ fragment of the relA gene with the resistance cassette. PCR analysis was performed on kanamycin-resistant clones to select for the vector with the kanamycin-resistance cassette in the same orientation as the relA gene. This vector was named pRel27, and was subsequently digested by EcoRI and SphI. The fragment containing the relA gene and the kanamycin-resistance vector was cloned into the conjugative plasmid pAT $\Delta$ S28, resulting in pRel37. This vector was used to generate deletion mutants of relA by filter mating (Trieu-Cuot et al., 1987; Pezard et al., 1991) of B. anthracis 7702 with E. coli HB101 carrying the plasmids pRK24 and pRel37. Deletion of relA in B. anthracis was confirmed by PCR analysis using primers on the kanamycinresistance cassette and outside the cloned fragment containing the relA gene (data not shown). The relA deletion was transferred to other genetic backgrounds by phage transduction with CP51, as described elsewhere (Green et al., 1985). The relA deletion mutant in the 7702 background was termed 7RelK.

Development of a defined medium for $B$. anthracis. A defined low-phosphate medium (DLPM) for culturing B. anthracis was based on a medium developed elsewhere for Bacillus cereus (Buono et al., 1966). The DLPM medium for B. anthracis contained MOPS (40 mM, pH 7.4) as buffering agent, $0.2 \mathrm{mM}$ of each amino acid, $0.1 \mathrm{mM} \mathrm{K}_{2} \mathrm{HPO}_{4}, 0.8 \mathrm{mM} \mathrm{MgSO}_{4}, 0.04 \mathrm{mM} \mathrm{MnCl}_{2}, 0.2 \mathrm{mM} \mathrm{NaCl}$, $10 \mathrm{mM} \mathrm{KCl}, 0.2 \mathrm{mM} \mathrm{CaCl}, 0.05 \mathrm{mM} \mathrm{ZnSO}, 0.04 \mathrm{mM} \mathrm{FeCl}$, $20 \mathrm{mM}$ glucose and $1 \mathrm{mg}$ thiamine hydrochloride $1^{-1}$. As an inoculum, $1 \mathrm{ml}$ of an overnight culture in $\mathrm{BHI}+0.5 \%$ glycerol was washed twice with $1 \mathrm{ml}$ DLPM and resuspended in an equal volume of DLPM. Subsequently, $20 \mathrm{ml}$ DLPM was inoculated with $20 \mu \mathrm{l}$ of the washed overnight culture and cultured at $37{ }^{\circ} \mathrm{C}$ as described above.

Measurement of RNA synthesis. RNA synthesis by $B$. anthracis was determined by measuring the incorporation of $\left[{ }^{3} \mathrm{H}\right]$ uridine, essentially as described by Lewis et al. (2000). B. anthracis was grown in DLPM to $\mathrm{OD}_{600}=0.15$. Subsequently $2 \mathrm{ml}$ aliquots of the culture were filtered using hydrophilic Durapore membrane filters $(0.45 \mu \mathrm{m}$ poresize, Millipore). The filters were then resuspended in $2 \mathrm{ml}$ prewarmed DLPM or DLPM with the amino acids isoleucine, leucine and valine (ILV) omitted (DPLM-ILV). In addition, the medium 
contained $\left[{ }^{3} \mathrm{H}\right]$ uridine $(10 \mu \mathrm{Ci} ; 370 \mathrm{kBq})$ and cold uridine $(0.1 \mathrm{mM})$. Aliquots of $250 \mu \mathrm{l}$ were removed and added to $1 \mathrm{ml}$ ice-cold $10 \%$ TCA. Samples were left on ice for at least $30 \mathrm{~min}$, after which total RNA was collected by filtration on Whatman GF/C glassfibre disks. Subsequently, filters were washed twice with $1 \mathrm{ml}$ ice-cold $10 \%$ TCA and once with $3 \mathrm{ml} 100 \%$ ethanol. $\left[{ }^{3} \mathrm{H}\right]$ Uridine incorporation was determined by scintillation counting.

Determination of intracellular (p)ppGpp levels. B. anthracis cultures were grown in DLPM to $\mathrm{OD}_{600}=0.03$. Next, $10 \mu \mathrm{Ci}{ }^{32} \mathrm{P}$ labelled $\mathrm{H}_{3} \mathrm{PO}_{4}$ was added to $1 \mathrm{ml}$ of culture, followed by further incubation at $37^{\circ} \mathrm{C}$ until the cultures reached $\mathrm{OD}_{600} 0.15$. Cultures were then filtered and resuspended in DLPM-ILV containing $10 \mu \mathrm{Ci}$ ${ }^{32} \mathrm{P}$-labelled $\mathrm{H}_{3} \mathrm{PO}_{4}$. Immediately prior to filtration $(t=0)$ and 5,10 , 20,30 and $40 \mathrm{~min}$ after resuspension of the filters in the growth medium, $20 \mu \mathrm{l}$ aliquots were removed and added to $20 \mu \mathrm{l} 12 \mathrm{M}$ formic acid. After three freeze-thaw cycles, $5 \mu \mathrm{l}$ aliquots were analysed on PEI/cellulose TLC plates (Macherey-Nagel) with $1.5 \mathrm{M}$ $\mathrm{KH}_{2} \mathrm{PO}_{4}$ as developing solution. Labelled nucleotides were visualized by autoradiography on film and Phosphoimager screens. To identify labelled nucleotides, ${ }^{32} \mathrm{P}$-labelled formic acid extracts of $E$. coli MG1655 were prepared as described below, and these were run adjacent to the B. anthracis extracts on the TLC plates. E. coli was grown in DLPM to $\mathrm{OD}_{600}=0.15$, after which cells were resuspended in DLPM from which all nitrogen sources were removed (DLPM-N) and incubated at $37^{\circ} \mathrm{C}$ for $10 \mathrm{~min}$. Aliquots $(20 \mu \mathrm{l})$ were removed before and after resuspension in DLPM-N, and labelled nucleotides were extracted as outlined above.

$\boldsymbol{\beta}$-Galactosidase assays. Expression of pagA and atxA during growth at $37{ }^{\circ} \mathrm{C}$ in $\mathrm{R}$ medium containing $0.6 \%$ (w/v) sodium bicarbonate was determined as previously described (Sirard et al., 1994) by using pagAlac $Z$ and atxA-lac $Z$ promoter reporter constructs integrated on $\mathrm{pXO} 1$ in both parental and relA-deleted backgrounds.

Animal experiments. Six female OF/1 (6-8 weeks old) mice (Charles River Laboratories) were injected subcutaneously with $5 \times 10^{4}, 5 \times 10^{5}$ or $5 \times 10^{6}$ spores per mouse of either B. anthracis 7702 or 7 RelK. Survival of the mice during infection was scored daily for 15 days. Kaplan-Meier survival curves were drawn and analysed using log rank analysis with GraphPad Prism 4 software (GraphPad Software). $\mathrm{LD}_{50}$ values were estimated by the Reed and Muench method (Reed \& Muench, 1938).

Determination of sporulation of $\boldsymbol{B}$. anthracis. Strains were grown in DLPM at $37{ }^{\circ} \mathrm{C}$ with shaking at 150 r.p.m. At regular intervals,
$1 \mathrm{ml}$ samples were taken and viable counts were determined using unheated (for total viable counts) and heated $\left(65^{\circ} \mathrm{C}, 20 \mathrm{~min}\right.$; for spore counts) samples. Serial dilutions of the samples in physiological saline $(0.9 \% \mathrm{NaCl})$ were plated on $\mathrm{BHI}$ plates. Plates were incubated for $18 \mathrm{~h}$ at $37^{\circ} \mathrm{C}$.

\section{RESULTS}

\section{relA-dependent (p)ppGpp accumulation and stringent response}

The gene encoding (p)ppGpp synthetase was identified in $B$. anthracis by searching the $B$. anthracis genome (Read et al., 2003) for genes encoding homologues of RelA from B. subtilis and L. monocytogenes (Wendrich \& Marahiel, 1997; Taylor et al., 2002). The protein encoded by gene BA4637 is 77 and $70 \%$ identical, respectively, to these two genes, and BA4637 was therefore termed relA. A deletion mutant for the relA gene, termed $B$. anthracis 7 RelK, was constructed by allelic replacement of a $1.6 \mathrm{~kb}$ internal fragment of BA4637 with a kanamycin-resistance cassette.

For our studies we developed a defined medium for $B$. anthracis (DLPM; see Methods). Amino acid auxotrophies of $B$. anthracis 7702 were determined by removing single amino acids from DLPM. By this 'drop-out' approach, the amino acids glycine, isoleucine, leucine, methionine, phenylalanine, serine and valine were found to be essential for growth of B. anthracis 7702 . The deletion of relA did not affect amino acid auxotrophies (data not shown).

In both E. coli and B. subtilis the removal of essential amino acids has been found to lead to the accumulation of (p)ppGpp (Cashel et al., 1996; Ochi et al., 1981). During exponential growth in DLPM and upon starvation for ILV, the accumulation of (p)ppGpp in B. anthracis was measured by TLC analysis (Fig. 1). In B. anthracis 7702, spots corresponding to (p)ppGpp could not be identified during exponential growth in DLPM. Five minutes after ILV starvation, (p)ppGpp accumulated. The levels of (p)ppGpp appeared to decrease somewhat over time. In

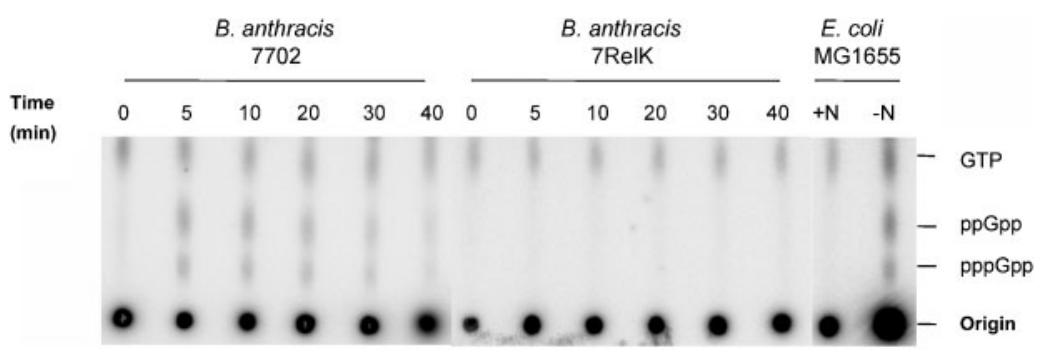

Fig. 1. relA-dependent accumulation of (p)ppGpp in B. anthracis upon starvation for ILV. B. anthracis 7702 and 7RelK were grown in DLPM to mid-exponential phase. Cultures were then filtered and the filters containing the cells were resuspended in DLPM-ILV. At the indicated times, aliquots were removed from the cultures, and ${ }^{32} \mathrm{P}$-labelled nucleotides were extracted and analysed by TLC. To identify labelled nucleotides of $B$. anthracis, ${ }^{32} \mathrm{P}$-labelled extracts of nitrogen-starved (DLPM-N) E. coli MG1655 were run adjacent to the $B$. anthracis extracts on the TLC plates. Results shown are representative of two independent experiments. 
7RelK, spots corresponding to (p)ppGpp were not present during exponential growth and did not appear upon starvation for ILV.

The defining characteristic of the stringent response is the down-regulation of RNA synthesis upon starvation for amino acids (Cashel et al., 1996). In B. anthracis the removal of ILV leads directly to a rapid down-regulation of RNA synthesis as measured by $\left[{ }^{3} \mathrm{H}\right]$ uridine incorporation in RNA (Fig. 2). In 7RelK, however, RNA synthesis was unchanged upon starvation for ILV. We conclude that $B$. anthracis exhibits a stringent response on starvation for essential amino acids and that this response is mediated through the relA gene, which is responsible for the accumulation of (p)ppGpp.

\section{Deletion of relA does not affect virulence}

To assess the effect of the relA gene on the transcription of pagA, which encodes the toxin component PA, we deleted the relA gene in strain RBAF140 (Sirard et al., 1994). This strain is isogenic to 7702 , but carries a transcriptional fusion of the promoter of $p a g A$ with a $\operatorname{lac} Z$ reporter gene on $\mathrm{pXO} 1$. The $\beta$-galactosidase activities of RBAF140 and its relA mutant were determined during growth in $\mathrm{R}$ medium supplemented with $0.6 \%$ sodium bicarbonate. During growth in $\mathrm{R}$ medium, pagA transcription reached maximum levels in B. anthracis RBAF140 in early stationary phase (Fig. 3). The deletion of relA did not influence the transcription of pagA during growth in $\mathrm{R}$ medium. The transcription of the atxA gene was also not significantly affected by the deletion of relA (data not shown). The virulence of the relA mutant was compared to that of the

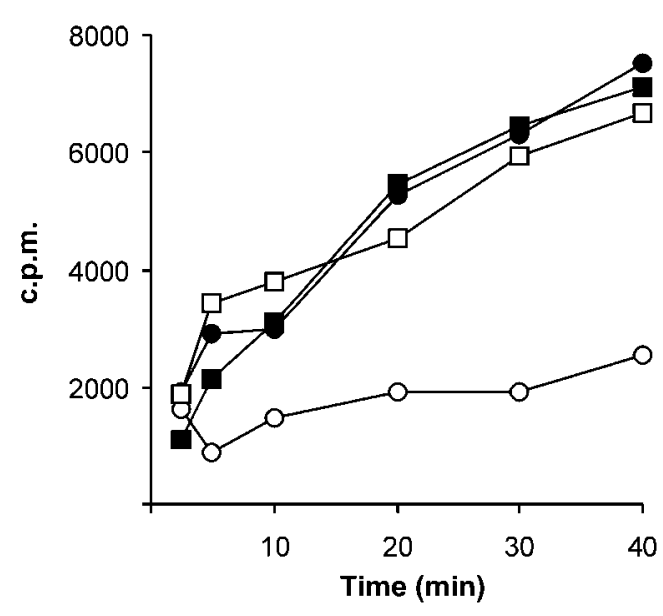

Fig. 2. The relA-dependent stringent response of $B$. anthracis. The synthesis of stable RNA was measured by $\left[{ }^{3} \mathrm{H}\right]$ uridine incorporation in TCA-precipitable material in B. anthracis 7702 (circles) and 7RelK (squares) during exponential growth in DLPM (closed symbols) and DLPM-ILV (open symbols). Results shown are representative of three independent experiments.

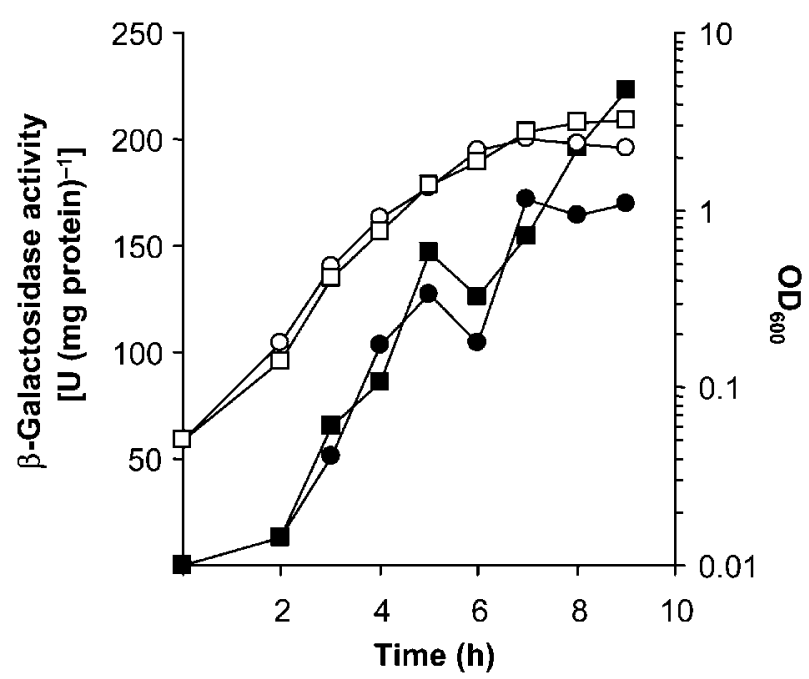

Fig. 3. Transcription of $\operatorname{pag} A$ in the wild-type strain and its isogenic relA deletion mutant. $B$. anthracis RBAF140 (circles) and its relA mutant (squares) were grown in $\mathrm{R}$ medium containing $0.6 \%$ sodium bicarbonate under a $5 \% \mathrm{CO}_{2}$ atmosphere. Growth was followed by $\mathrm{OD}_{600}$ measurements (open symbols) and transcription of $\operatorname{pag} A$ was determined by measuring $\beta$-galactosidase activity (closed symbols). Results shown are representative of three independent experiments.

parental 7702 strain in a mouse model of anthrax. Estimated $\mathrm{LD}_{50}$ values were essentially the same for the 7702 and 7RelK strains, at $2.5 \times 10^{4}$ and $2.4 \times 10^{4}$ spores per mouse, respectively. Both these results demonstrate that relA and the stringent response do not play a significant role in the virulence of $B$. anthracis. As capsulation was not affected by the deletion of relA in the capsulated RPG1 strain (data not shown), it was deemed unethical to perform animal experiments with RPG1 and its relA mutant, as capsulation is the sole determining factor of virulence in non-toxinogenic strains (Welkos et al., 1993).

\section{Deletion of relA diminishes sporulation}

To study the effect of relA on sporulation, B. anthracis 7702 and 7RelK were grown in DLPM, and at regular intervals, total viable counts and spore counts were determined (Fig. 4). The wild-type strain sporulated readily and efficiently in this medium, reaching spore titres of $3.6 \times 10^{6} \mathrm{ml}^{-1}$ after only $14 \mathrm{~h}$. After $24 \mathrm{~h}$ and at later time points, both the spore counts and the total viable counts for 7702 were essentially the same at $2.4 \times 10^{7} \mathrm{ml}^{-1}$, indicating complete sporulation. Final spore counts in the 7RelK culture were only $1 \times 10^{3} \mathrm{ml}^{-1}$. The remaining vegetative cells of 7RelK started to die off after $48 \mathrm{~h}$ of growth in DLPM, presumably due to their inability to adapt to and survive in nutrient-poor conditions. 


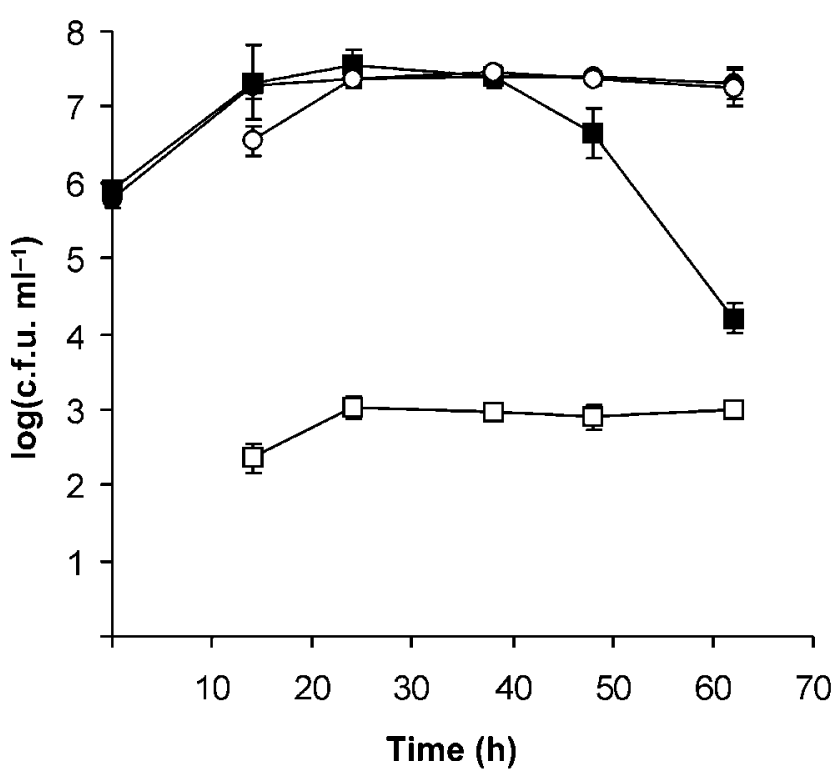

Fig. 4. Effect of the deletion of $r e / A$ on sporulation of $B$. anthracis. Strains 7702 (circles) and 7RelK (squares) were grown in DLPM at $37{ }^{\circ} \mathrm{C}$. Total viable counts (closed symbols) and spore counts (open symbols) were determined. The results are the mean of three independent experiments and SD is indicated by the error bars.

\section{DISCUSSION}

In this article we show that $B$. anthracis exhibits a rapid down-regulation of RNA synthesis upon starvation of the essential amino acids ILV. Upon removal of these amino acids, the hyperphosphorylated nucleotides ppGpp and pppGpp accumulate, and the gene relA was determined to be responsible for the biosynthesis of (p)ppGpp. Deletion of the relA gene did not affect the production of virulence factors or virulence in a mouse model, but had a large effect on sporulation.

Whereas it has long been known that in B. anthracis entry into the stationary growth phase coincides with maximal production of toxin components (Sirard et al., 1994), the environmental cues that lead to this response are still unknown. On the basis of our findings, starvation for amino acids and the resulting stringent response can be ruled out as a trigger that leads to the production of the $B$. anthracis virulence factors. However, it cannot be ruled out that other regulatory mechanisms that react to amino acid levels have a role in controlling the production of virulence factors in B. anthracis.

It appears that in both $B$. anthracis and the Gram-positive model organism B. subtilis, an important function of the stringent response is conserved, i.e. priming of cells that undergo nutrient starvation to go into sporulation. In nonspore-forming pathogenic Gram-positive bacteria, the effects on virulence do not appear to be a consequence of a stringent response-dependent upregulated expression of specific virulence factors, but rather a more pleiotropic effect on microbial metabolism, which can result in lower growth rates or the loss of certain phenotypes (such as biofilm formation) that can confer a competitive advantage during infection (Taylor et al., 2002; Dahl et al., 2003; Lemos et al., 2004). As no major effect of the deletion of relA on both the production of virulence factors and the growth kinetics of $B$. anthracis was observed, our finding that the relA deletion mutant is as virulent as the parental $B$. anthracis strain is not unexpected.

Interestingly, the sporulation of $B$. anthracis was strongly affected in a relA deletion mutant. This shows that the stringent response of $B$. anthracis is important in signalling nutrient starvation and priming the cells to sporulate. The mechanistic pathway linking the stringent response to sporulation remains to be determined in B. anthracis, and may involve a decrease in GTP levels due to the inhibitory action of (p)ppGpp on the enzyme inosine monophosphate dehydrogenase, which has been shown to be a target for (p)ppGpp in several bacteria, including B. subtilis (Ochi et al., 1981; Ochi, 1987; Kasai et al., 2006).

The important role of the stringent response in the sporulation of $B$. anthracis has implications for the understanding of the mechanisms that are involved in the infectious cycle of $B$. anthracis, since the spore is the persistent form of $B$. anthracis in the natural environment and is the infectious form that is needed to cause the disease anthrax in the mammalian host. Consequently, the stringent response appears to contribute significantly to the ecological success of $B$. anthracis as a mammalian pathogen.

\section{ACKNOWLEDGEMENTS}

The authors wish to thank Michèle Mock for her constant interest in this project and Professor Richard D'Ari for helpful discussions. W.v. S. was funded through an EMBO Long-Term Fellowship.

\section{REFERENCES}

Bourgogne, A., Drysdale, M., Hilsenbeck, S. G., Peterson, S. N. \& Koehler, T. M. (2003). Global effects of virulence gene regulators in a Bacillus anthracis strain with both virulence plasmids. Infect Immun 71, 2736-2743.

Braeken, K., Moris, M., Daniels, R., Vanderleyden, J. \& Michiels, J. (2005). New horizons for (p)ppGpp in bacterial and plant physiology. Trends Microbiol 14, 45-54.

Buono, F., Testa, R. \& Lundgren, D. G. (1966). Physiology of growth and sporulation in Bacillus cereus. I. Effect of glutamic and other amino acids. J Bacteriol 91, 2291-2299.

Candela, T. \& Fouet, A. (2005). Bacillus anthracis CapD, belonging to the $\gamma$-glutamyltranspeptidase family, is required for the covalent anchoring of capsule to peptidoglycan. Mol Microbiol 57, 717-726.

Candela, T., Mock, M. \& Fouet, A. (2005). CapE, a 47-amino-acid peptide, is necessary for Bacillus anthracis polyglutamate capsule synthesis. J Bacteriol 187, 7765-7772.

Cashel, M., Gentry, D. R., Hernandez, V. J. \& Vinella, D. (1996). The stringent response. In Escherichia coli and Salmonella: Cellular and 
Molecular Biology, 2nd edn, pp. 1458-1496. Edited by F. C. Neidhardt and others. Washington, DC: American Society for Microbiology.

Dahl, J. L., Kraus, C. N., Boshoff, H. I., Doan, B., Foley, K., Avarbock, D., Kaplan, G., Mizrahi, V., Rubin, H. \& Barry, C. E., III (2003). The role of RelMtb-mediated adaptation to stationary phase in long-term persistence of Mycobacterium tuberculosis in mice. Proc Natl Acad Sci U S A 100, 10026-10031.

Dragon, D. C., Bader, D. E., Mitchell, J. \& Woollen, N. (2005). Natural dissemination of Bacillus anthracis spores in northern Canada. Appl Environ Microbiol 71, 1610-1615.

Eymann, C., Mittenhuber, G. \& Hecker, M. (2001). The stringent response, $\sigma^{\mathrm{H}}$-dependent gene expression and sporulation in Bacillus subtilis. Mol Gen Genet 264, 913-923.

Fouet, A. \& Mock, M. (1996). Differential influence of the two Bacillus anthracis plasmids on regulation of virulence gene expression. Infect Immun 64, 4928-4932.

Fouet, A. \& Mock, M. (2006). Regulatory networks for virulence and persistence of Bacillus anthracis. Curr Opin Microbiol 9, 160-166.

Gimenez, A. P., Wu, Y. Z., Paya, M., Delclaux, C., Touqui, L. \& Goossens, P. L. (2004). High bactericidal efficiency of type IIA phospholipase $\mathrm{A}_{2}$ against Bacillus anthracis and inhibition of its secretion by the lethal toxin. J Immunol 173, 521-530.

Green, B. D., Battisti, L., Koehler, T. M. \& Thorne, C. B. (1985). Demonstration of a capsule plasmid in Bacillus anthracis. Infect Immun 49, 291-297.

Guidi-Rontani, C., Weber-Levy, M., Labruyere, E. \& Mock, M. (1999). Germination of Bacillus anthracis spores within alveolar macrophages. Mol Microbiol 31, 9-17.

Guignot, J., Mock, M. \& Fouet, A. (1997). AtxA activates the transcription of genes harbored by both Bacillus anthracis virulence plasmids. FEMS Microbiol Lett 147, 203-207.

Hadjifrangiskou, M., Chen, Y. \& Koehler, T. M. (2007). The alternative sigma factor $\sigma^{\mathrm{H}}$ is required for toxin gene expression by Bacillus anthracis. J Bacteriol 189, 1874-1883.

Jensen, G. B., Hansen, B. M., Eilenberg, J. \& Mahillon, J. (2003). The hidden lifestyles of Bacillus cereus and relatives. Environ Microbiol 5, 631-640.

Kasai, K., Nishizawa, T., Takahashi, K., Hosaka, T., Aoki, H. \& Ochi, K. (2006). Physiological analysis of the stringent response elicited in an extreme thermophilic bacterium, Thermus thermophilus. J Bacteriol 188, 7111-7122.

Lemos, J. A., Brown, T. A., Jr \& Burne, R. A. (2004). Effects of RelA on key virulence properties of planktonic and biofilm populations of Streptococcus mutans. Infect Immun 72, 1431-1440.

Lewis, P. J., Thaker, S. D. \& Errington, J. (2000). Compartmentalization of transcription and translation in Bacillus subtilis. EMBO J 19, 710-718.

Mignot, T., Mock, M. \& Fouet, A. (2003). A plasmid-encoded regulator couples the synthesis of toxins and surface structures in Bacillus anthracis. Mol Microbiol 47, 917-927.

Mittenhuber, G. (2001). Comparative genomics and evolution of genes encoding bacterial (p)ppGpp synthetases/hydrolases (the Rel, RelA and SpoT proteins). J Mol Microbiol Biotechnol 3, 585-600.

Mock, M. \& Fouet, A. (2001). Anthrax. Annu Rev Microbiol 55, 647-671.

Ochi, K. (1987). Changes in nucleotide pools during sporulation of Streptomyces griseus in submerged culture. J Gen Microbiol 133, 2787-2795.
Ochi, K., Kandala, J. C. \& Freese, E. (1981). Initiation of Bacillus subtilis sporulation by the stringent response to partial amino acid deprivation. J Biol Chem 256, 6866-6875.

Pezard, C., Berche, P. \& Mock, M. (1991). Contribution of individual toxin components to virulence of Bacillus anthracis. Infect Immun 59, 3472-3477.

Read, T. D., Peterson, S. N., Tourasse, N., Baillie, L. W., Paulsen, I. T., Nelson, K. E., Tettelin, H., Fouts, D. E., Eisen, J. A. \& other authors (2003). The genome sequence of Bacillus anthracis Ames and comparison to closely related bacteria. Nature 423, 81-86.

Reed, L. J. \& Muench, H. (1938). A simple method of estimating fifty percent endpoints. Am J Hyg 27, 493-497.

Saile, E. \& Koehler, T. M. (2002). Control of anthrax toxin gene expression by the transition state regulator abrB. J Bacteriol 184, 370-380.

Saile, E. \& Koehler, T. M. (2006). Bacillus anthracis multiplication, persistence, and genetic exchange in the rhizosphere of grass plants. Appl Environ Microbiol 72, 3168-3174.

Sirard, J. C., Mock, M. \& Fouet, A. (1994). The three Bacillus anthracis toxin genes are coordinately regulated by bicarbonate and temperature. J Bacteriol 176, 5188-5192.

Strauch, M. A., Ballar, P., Rowshan, A. J. \& Zoller, K. L. (2005). The DNA-binding specificity of the Bacillus anthracis AbrB protein. Microbiology 151, 1751-1759.

Taylor, C. M., Beresford, M., Epton, H. A., Sigee, D. C., Shama, G., Andrew, P. W. \& Roberts, I. S. (2002). Listeria monocytogenes relA and $h p t$ mutants are impaired in surface-attached growth and virulence. J Bacteriol 184, 621-628.

Trieu-Cuot, P. \& Courvalin, P. (1983). Nucleotide sequence of the Streptococcus faecalis plasmid gene encoding the $3^{\prime} 5^{\prime \prime}$-aminoglycoside phosphotransferase type III. Gene 23, 331-341.

Trieu-Cuot, P., Carlier, C., Martin, P. \& Courvalin, P. (1987). Plasmid transfer by conjugation from Escherichia coli to Gram-positive bacteria. FEMS Microbiol Lett 48, 289-294.

Tsvetanova, B., Wilson, A. C., Bongiorni, C., Chiang, C., Hoch, J. A. \& Perego, M. (2007). Opposing effects of histidine phosphorylation regulate the AtxA virulence transcription factor in Bacillus anthracis. Mol Microbiol 63, 644-655.

Uchida, I., Hornung, J. M., Thorne, C. B., Klimpel, K. R. \& Leppla, S. H. (1993). Cloning and characterization of a gene whose product is a trans-activator of anthrax toxin synthesis. J Bacteriol 175, 5329-5338.

Van Ness, G. B. (1971). Ecology of anthrax. Science 172, 1303-1307. Welkos, S. L., Vietri, N. J. \& Gibbs, P. H. (1993). Non-toxigenic derivatives of the Ames strain of Bacillus anthracis are fully virulent for mice: role of plasmid pX02 and chromosome in strain-dependent virulence. Microb Pathog 14, 381-388.

Wendrich, T. M. \& Marahiel, M. A. (1997). Cloning and characterization of a relA/spoT homologue from Bacillus subtilis. Mol Microbiol 26, 65-79.

White, A. K., Hoch, J. A., Grynberg, M., Godzik, A. \& Perego, M. (2006). Sensor domains encoded in Bacillus anthracis virulence plasmids prevent sporulation by hijacking a sporulation sensor histidine kinase. J Bacteriol 188, 6354-6360.

Edited by: K. M. Devine 